\title{
THE EDUCATIONAL AND CAREER BACKGROUNDS OF CIOS
}

\author{
John Anderson, Utah Valley University, janderson@uvu.edu \\ Nicholas Ball, Utah ValleyUniversity, nicholas.ball@uvu.edu
}

\begin{abstract}
The lead IS Manager role has changed over the last forty years from a technician managing a service function to a CIO executive with the potential to have a substantial strategic impact on the organization. However, unlike many of the other C-Level executives, the CIO manages a very technical staff, and there is still a controversy as to whether the $C I O$ is half technician and half manager/strategist, or shed the technology role to be mostly manager/strategist. What is the education of CIOs? What are the job roles they have before they become CIO? Our survey data suggest that most CIOs come from business rather than computing education, most CIOs used business rather than computing skills in the last position they had before becoming CIO, most CIOs are concerned with and use business rather than computing skills in their current position as CIO.
\end{abstract}

\section{INTRODUCTION}

$\mathrm{CIO}$ research has been performed for over forty years with many interesting articles and findings. The genesis article is probably B. Ives and M. Olson's 1981 MIS Quarterly article "Manager of Technician? The Nature of the Information Systems Manager's Job." They found that the IS Manager evolved from a technician managing a relatively unimportant service function in the 1960s to a vice presidential-level general manager of a department with substantial organizational impact by 1981 . They looked at daily activities, and especially at the nature of oral contacts that constitute $76 \%$ of their daily tasks. $54 \%$ of the subjects of the message units were related to general administration and operations. Interpersonal and motivational skills are relied on. The IS Manager was surrounded by technical specialists who provided expertise as required. Rather than focus on day-to-day operations the IS Manager spent more time planning IS strategy and human resource concerns.

As a follow-on study, a 1992 MIS Quarterly article "Executive or Functional Manager? The Nature of the CIO's Job" C. Stephens, W. Ledbetter, A. Mitra, and N. Ford looked at the role of the CIO, and how this role is different from the MIS manager. The CIO role was meant to bridge the gap between the organization's strategy and its use of information technology. They found that the CIO operates as an executive rather than a functional manager. CIOs participate in strategy planning act as a bridge between IT and functional and external entities. Important factors for CIO success were resource allocation authority and level of peer acceptance.

There have been many articles discussing the CIO role and success factors with a mix of findings that the CIO is actually more of technical manager than other executives, while others find that the CIO is more of strategic executive. The 2010 California Management Review article "Unlocking the Performance of the Chief Information Officer" J Peppard noted that the CIO role had changed from the strategist-bridge function to a new mandate of finding ways IT can change the company, a broader role of business transformation and innovation. He also pointed out that in 2010 the dominant point of view was that CIO lack leadership skills, don't participate in strategy, have little credibility with their colleagues, are seen as not having built relationships at appropriate levels, and deficient in communication and influencing skills. While conducting interviews, Peppard found that the CIO is a confused role in the executive suite as to what exactly defines a CIO. However, Peppard also found that the CIO is first and foremost a business leader, and having a business perspective is more important than a technical perspective. The competencies most important to success were: leadership, visionary, strategic thinker, relationship builder, diplomat, deliverer, and reading the market. Peppard noted many examples of IT Managers being raised to CIO and failing because of lack of these business skills. He also found that IT savviness of the CEO and senior leadership along with a good CIO are important to realizing the value of IT in organizations.

J. Spitze and J. Lee in their 2012 California Management Review article "The Renaissance CIO Project: The Invisible Factors of Extraordinary Success" found that the three most important success factors of a CIO were that: CIOs must be life-long learners, must be able to build and motivate cross-functional teams marshalling collective intelligence, must be able to conceive and implement a customer-facing game-changing project. These are all business skills not computer technology related skills. 
In this study we examine the educational and experiential backgrounds of CIOS. We assert that much can be inferred about the nature of the CIO position by studying the backgrounds of those who assume those positions. Specifically, our research questions are: What is the educational background of CIOs? What are the job roles they have before they become CIO?

\section{RESEARCH METHODOLOGY}

A survey was mailed to 2754 CIOs that came from an online database that listed corporate CIOs and were chosen because their company had sales over $\$ 100,000,000.233$ usable responses were returned for a response rate of $8.5 \%$. Descriptive statistics were utilized to explore the education, skills, and previous position of the CIOs.

\section{RESULTS}

Most CIOs have do not have a computer-related degree. As seen in Figure 1 below approximately $65 \%$ of CIO had a non-computer Bachelors degree, while only $35 \%$ had a computer related Bachelors degree. At the graduate degree educational level we see that $74 \%$ had a non-computer related graduate degree, while only $26 \%$ had a computer related graduate degree.

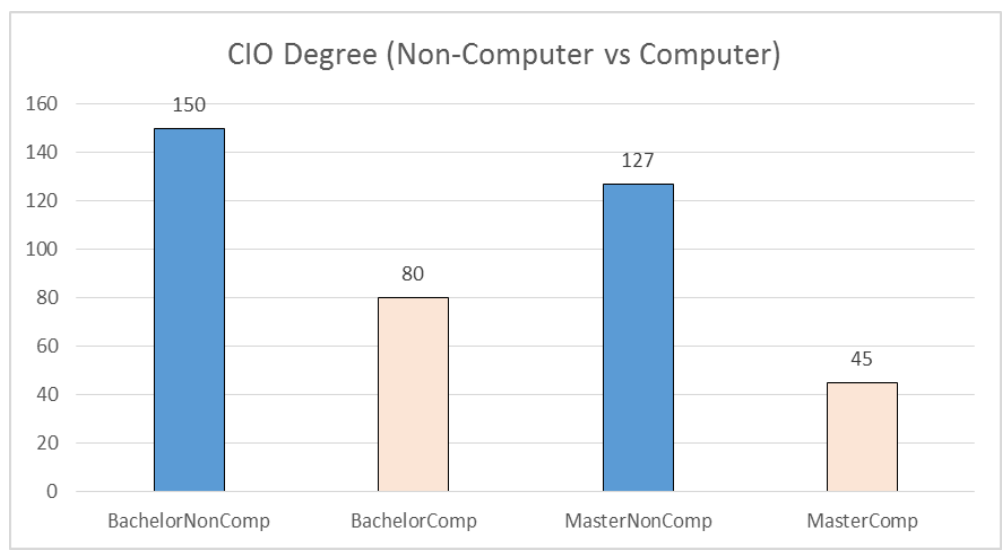

Figure 1. CIO Degree (Non-Computer vs. Computer)

Drilling-down into the Bachelors degree in Figure 2 we see that 39\% of Bachelors degrees where in Business (non IS/IT), $12 \%$ were in Science, $8 \%$ were in Engineering, $4 \%$ were in Liberal Arts, and 2\% in other. Computer-related degrees were $17 \%$ in Computer Science, $16 \%$ in IS/MIS/CIS, and $2 \%$ in IT. At the undergraduate level, a strong plurality of CIOs obtain non-IS business degrees.

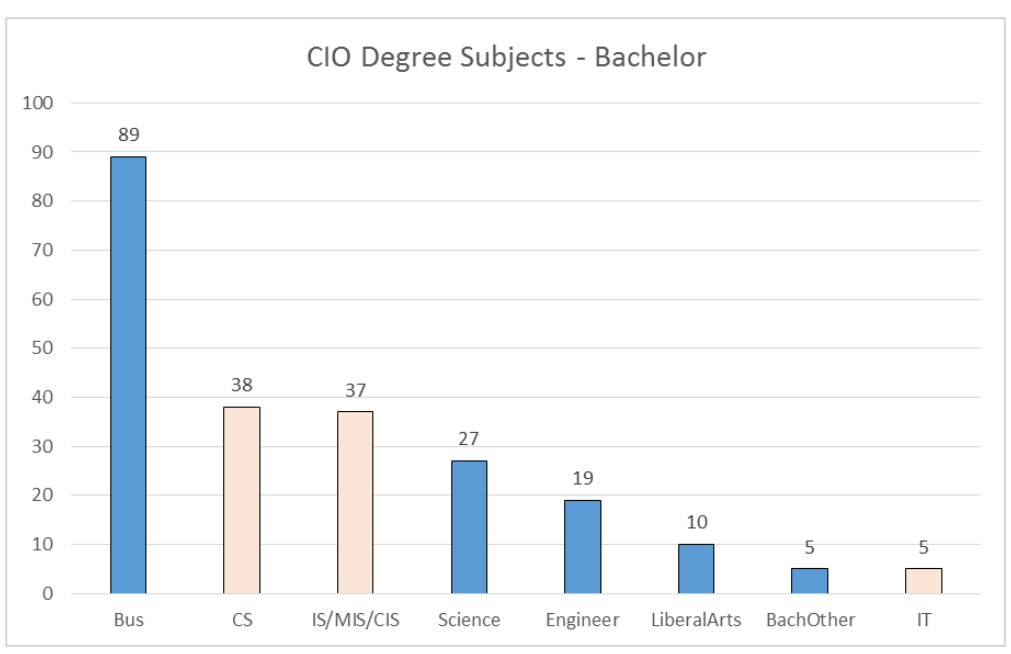

Figure 2. CIO Degree Subjects- Bachelor 
At the graduate level, Figure 3 illustrates that $35 \%$ of graduate degrees attained by CIOs were non-computer related MBA degrees, with $12 \%$ other masters degree, $6 \%$ master of science, $6 \%$ master of Accounting or Marketing, $4 \%$ non-computer $\mathrm{PhD}$, and about $2 \%$ master of engineering and liberal arts. While $8 \%$ had a master of IS, $7 \%$ had a MBA with an IS/IT emphasis, $6 \%$ had a master of computer science, $3 \%$ had a computer-related $\mathrm{PhD}$, and $1 \%$ had a masters in IT. As it was at the undergraduate level, most CIOs earn non-IS business master's degrees. The numbers are even more dramatic at eh graduate level. The ratio of non-IS business degrees to IS business degrees at the undergraduate level is slightly more than $2: 1$. At the graduate level, this ratio is nearly $3: 1$.

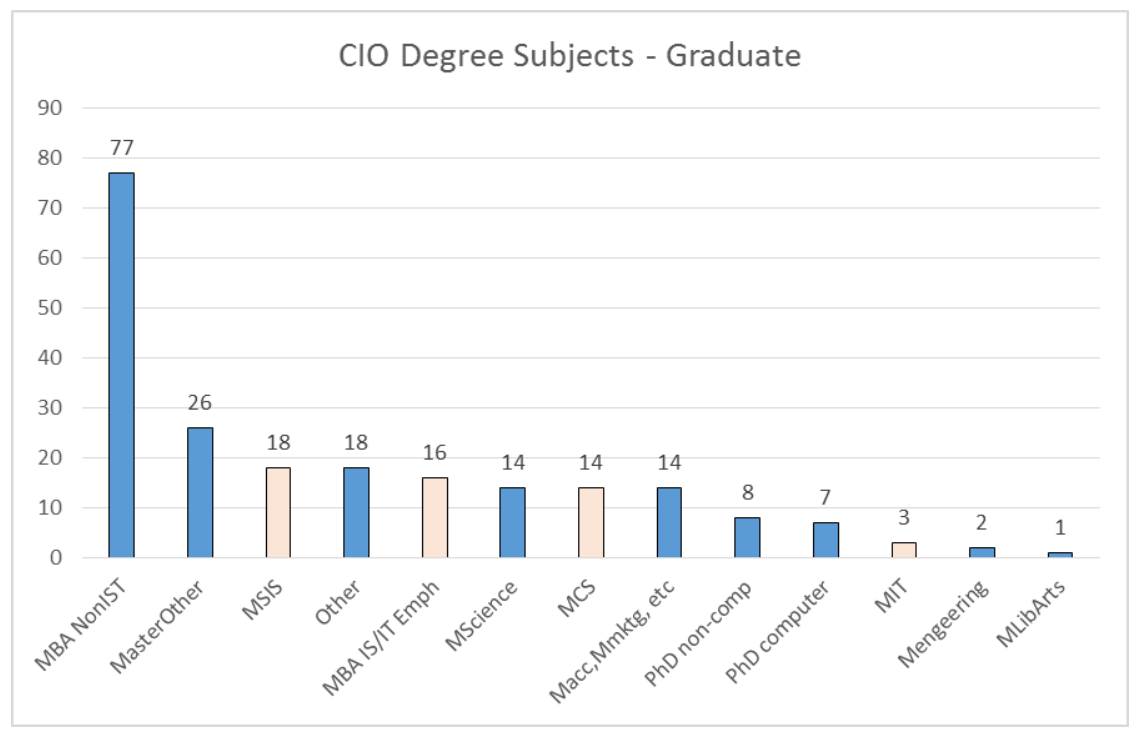

Figure 3. CIO Degree Subjects- Graduate

It is interesting the area of the respondent's last position before becoming CIO was found to be $56 \%$ non-computing related and $44 \%$ computing related. Figure 4 shows the non-computing positions with the five largest categories were: project management (19\% overall, $33 \%$ of non-computing); strategic IS planning (11\%), operations/logistics $(6 \%)$, accounting/finance (5\%), strategic business planning (5\%) respectively. Looking at computing related positions the six largest categories were: application development (19\% overall, $42 \%$ of computing); IS infrastructure management ( $9 \%$ overall, $20 \%$ of computing); ERP implementation and management ( $7 \%$ overall, $15 \%$ of computing); business analysis ( $5 \%$ overall, $11 \%$ of computing); IS integration management (3\% overall, $6 \%$ of computing); database design and management ( $2 \%$ overall, $5 \%$ of computing). 


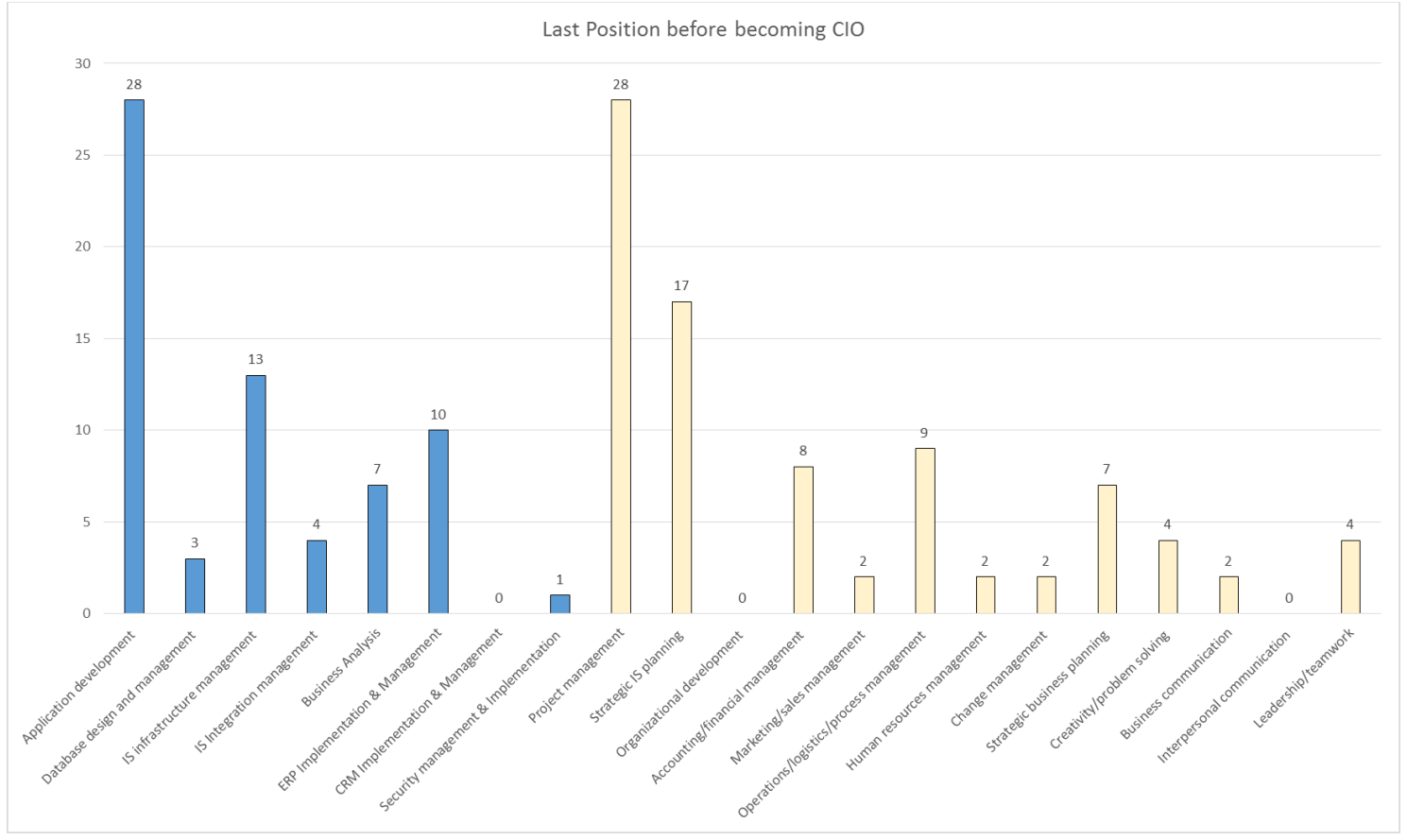

Figure 4. Last Position Before Becoming CIO

The areas most important to respondents as CIOs are shown in Figure 5 below: leadership/teamwork (40\%); strategic IS planning (17\%); strategic business planning (11\%); creativity/problem solving (8\%); interpersonal communication $(5 \%)$; change management $(4 \%)$; business communication $(3 \%)$; and organizational development (3\%). All of the computing skills were $2 \%$ or lower in importance. Clearly, when asked to rank the importance of each area to their position, CIOs report leadership and managerial skills as much more important that technical skills.

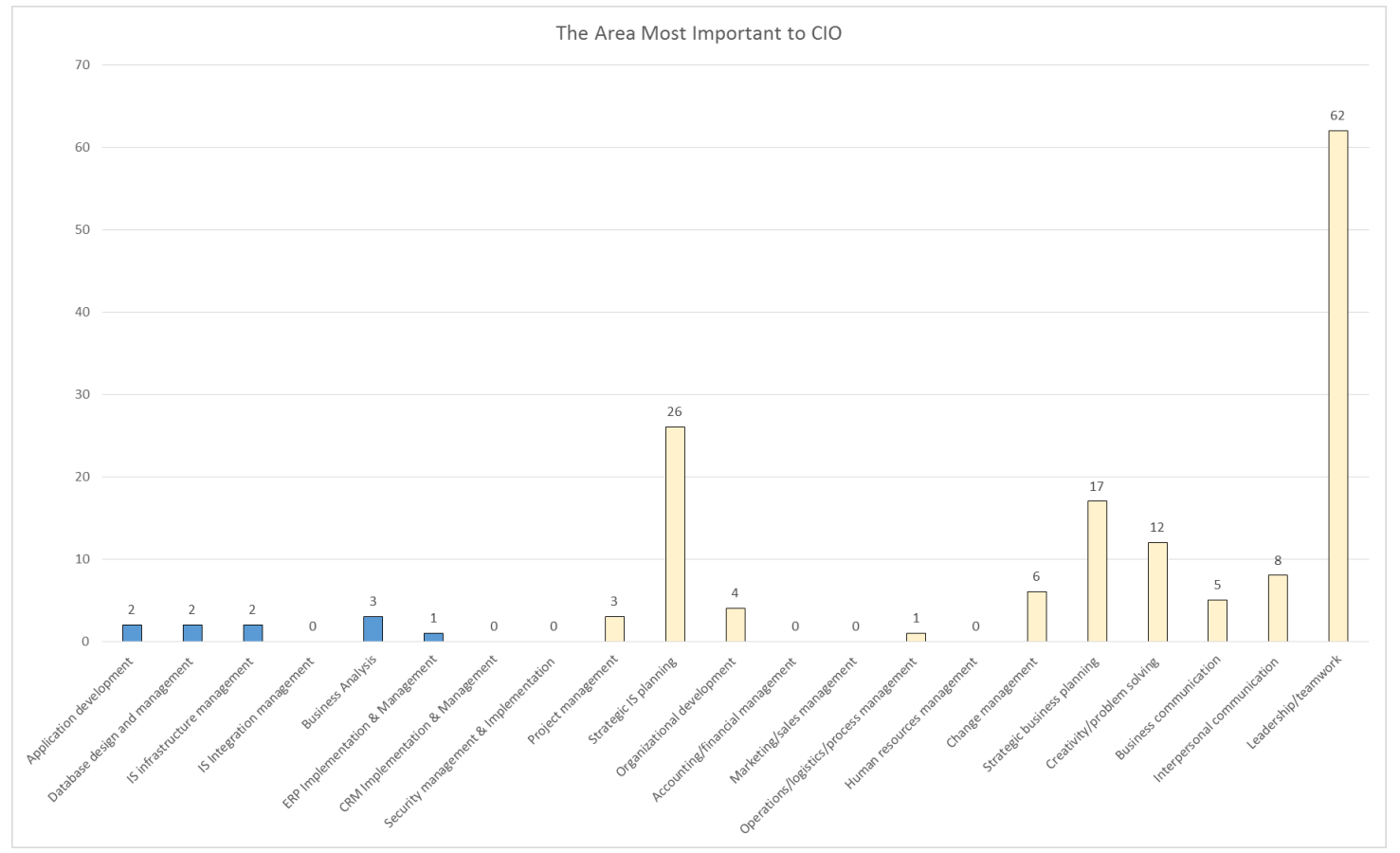

Figure 5. The Area Most Important to CIO 


\section{DISCUSSION}

Our results clearly show a bias toward the CIO as a business manager rather than a technician. This was to be expected as the literature review suggested that the CIO is more of a manager/strategist than technical manager. We were a bit surprised by how dramatically our data supported conclusion.

From the educational perspective, there is strong evidence that CIOs come from more managerial backgrounds than technical backgrounds. This is particularly true at the graduate level. Given that most business schools require fulltime work experience for admission to graduate programs, it may well be that the career path chosen by those who eventually become CIOs suggests a need for managerial training.

This assertion is supported by the nature of the last position CIOs hold before becoming CIO. Again, it appears that the career path of a CIO tends to go through more managerial positions - particularly just before becoming CIO.

The reported importance of skill sets in each area provides even strong evidence of the managerial nature of the CIO position. Leadership and managerial skills were ranked dramatically higher by CIOs than technical skills.

There are two possible reasons for these educational and experiential trends. Likely, the nature of the CIO position requires a stronger managerial than technical background. This is consistent with the conversations in the literature. It may also be that those hiring CIOs - high level executives from other business disciplines - are more comfortable choosing at top information executive with a business background. While those is likely related to the managerial nature of the CIO position, it may also be the case that executives from other business disciplines are more capable of evaluating candidates with managerial backgrounds than technical backgrounds.

There are at least two natural next steps that follow from this research. First, we did not examine the performance of any of the CIOs in our study. It would be interesting to determine if CIOs from managerial backgrounds were also more successful than those from technical backgrounds.

A second interesting line of research would examine if industry or firm characteristics determine the nature of the CIO position. Are firms in more technical or information intensive industries more likely to hire CIOs with a technical background than those in less technical or information intensive industries? This research could uncover reasons why companies have a $\mathrm{CIO}$ from a more technical background.

\section{CONCLUSIONS}

Our conclusions from this descriptive research are that:

- CIOs come from business rather than computing education.

- Most CIOs used business rather than computing skills in the last position they had before becoming CIO.

- CIO position is primarily concerned with business rather than computing skills.

- Most CIOs are concerned with and use business rather than computing skills in their current position as CIO.

\section{REFERENCES}

1. B. Ives and M. Olson (1981) "Manager of Technician? The Nature of the Information Systems Manager's Job." MIS Quarterly

2. J. Peppard (2010) California Management Review article "Unlocking the Performance of the Chief Information Officer"

3. J. Spitze and J. Lee (2012) "The Renaissance CIO Project: The Invisible Factors of Extraordinary Success" California Management Review

4. C. Stephens, W. Ledbetter, A. Mitra, and N. Ford (1992) "Executive or Functional Manager? The Nature of the CIO’s Job" MIS Quarterly 